\title{
MJN \\ PERCEPTION OF JOB SATISFACTION AMONG OPERATION ROOM NURSES IN A TERTIARY HOSPITAL, SAUDI ARABIA
}

\author{
Ong Khai-Lee, Chang Woan-Ching, Yee Bit-Lian* \\ International Medical University, Malaysia \\ *Corresponding Author's E-mail: bitlianyee@imu.edu.my
}

\begin{abstract}
Introduction: Nurses are Saudi Arabia's largest healthcare provider group for health promotion and disease prevention. The study aims to assess factors contributing on job satisfaction among the operation room (OR) nurses employed in a tertiary hospital, the capital of Saudi Arabia. Methodology: This study used descriptive and cross-sectional design. Total of 122 registered OR nurses participated in the study using self-administered questionnaires. Results: The findings of the study revealed that work-life balance of the OR nurses was the main factor affecting their job satisfaction. Discussion: This study determined the work-life balance as a main factor that influences the job satisfaction of nurses working in a tertiary hospital in Saudi Arabia. The results aligned with the information presented in the past literature that workload in the operating rooms, lack of job security, and lack of motivation affect job satisfaction among nurses.
\end{abstract}

Keywords: Job Satisfaction, Nurses, Work-Life Balance, Tertiary Hospital

\section{INTRODUCTION}

In Saudi Arabia, there is a rapid improvement and gradual development in healthcare system and infrastructure. However, nurse shortage and instability in the number of Saudi nurses working in hospitals has been a critical issue for policymakers in health system (AlMahmoud, Mullen, \& Spurgeon, 2012; Alostaz, 2016). Most nurses working in Saudi healthcare system are from other countries. If these nurses leave for a reason, the healthcare system and public hospitals in Saudi Arabia may face a crisis. Al-Mahmoud, Mullen, \& Spurgeon (2012) explained that nurse shortage is a national problem because of the limited number of nurses graduating from nursing schools or colleges.

Working as an expatriate in Saudi Arabia is highly rewarding and without having to pay tax. Expatriate nurses are from different countries, and they work on yearly contracts to deliver quality healthcare. Once the expatriate nurse arrives in the country, they are received by representatives from Meet and Greet Department at the airport and accompany them to StaffHousing Department. On the first day, all newly employed nurses should report to the Orientation Coordinator of the Staff Support Department. All new nurses go through a New Employee
General Orientation Program and Departmental Orientation Program.

According to Al-Dossary, Vail \& Macfarlane (2012), nursing job satisfaction is essential for healthcare system to reduce cases of nurse shortage and to achieve and maintain stable workforce. Previously conducted studies showed that working environment, educational level, teamwork, and work experience influence job satisfaction of nurses, which influence productivity of nurses and achievement of improved outcomes (Admasu et al., 2018; Alzahrani, Jones \& Abdel-Latif, 2018; Lamadah \& Sayed, 2014). Saudi Arabia is facing high turnover and significant nurse shortage because of job dissatisfaction. As a result, the country needs to recruit and retain more Saudi nurses (Alboliteeh, Magarey \& Wiechula, 2017). Exploring job satisfaction levels among Saudi Arabian nurses is crucial as it would assist healthcare managers in supporting healthcare policymakers with enough information on factors that affect job satisfaction among nurses working in Saudi hospitals (AL-Dossary et al., 2012). This study aimed to identify factors affecting levels of job satisfaction among Saudi Arabian nurses working in the operating rooms $(\mathrm{OR})$ in a tertiary hospital. 


\section{Objective}

Research objectives of the study to determine the factors affecting job satisfaction among operation room (OR) nurses employed in a tertiary hospital, Saudi Arabia.

\section{METHODOLOGY}

\section{Study design}

A descriptive cross-sectional design was used in this study to identify the factors affecting job satisfaction among OR nurses working in a tertiary hospital, Saudi Arabia.

\section{Setting}

The study was conducted in the (OR) of the tertiary hospital in the capital of Saudi Arabia. The hospital located in a major city at a region of Saudi Arabia. The hospital has 1600 beds and is considered as one of the most established hospitals in the Kingdom of Saudi Arabia.

\section{Participants}

For inclusion criteria, the study included both female and male Registered OR nurses who were working full time and with working experience of 6 months and above. Based on exclusion criteria, OR nurses holding a managerial position, and those with less than six months of working experience were not recruited to the study. Convenient sampling method was used in this study.

\section{Instrument}

Data were collected using self-administered questionnaires. Section A included a demographic data on gender, age, professional qualification, years of nursing experience, and years of practice in the current organisation were collected. Section B used the Minnesota Satisfaction Questionnaire (MSQ) to determine job satisfaction factors among OR nurses in a tertiary hospital, Saudi Arabia's capital. MSQ was available under a Creative Commons Attribution-NonCommercial (CC BY-NC 4.0) 4.0 International License. The license allowed the tool to be used free of charge and without a written consent for academic or clinical research, provided that the researchers identify the credit of the Vocational Psychology Research University of Minnesota. The MSQ was the source of the material in printed or digital replicated materials (University of Minnesota, 2016). The short version of
MSQ was adopted to obtain data in this study. The questionnaire consisted of 20 items, including intrinsic factor (12 items) and extrinsic factors (8 items). A 5point Likert scale rating from 1 (very dissatisfied), 2 (dissatisfied), 3 (neutral), 4 (satisfied) to 5 (very satisfied) was used.

A panel of two experts, including the assistant nursing supervisor and clinical nursing coordinator, were consulted to assist in determining the content validity of the survey. A pilot study was conducted before the main study. The questionnaire was piloted on 30 nurses from a OR under the same organisation to determine reliability of the instrument. The respondents from the pilot study were excluded from the main study. Cronbach alpha value of 0.75 obtained from the pilot study indicating an acceptable reliability (Grove et al., 2015). Hence, all items in the instrument are remained no change.

\section{Study size}

The population size of OR nurses in the tertiary care hospital was 154. Based on the Raosoft software, the minimum recommended sample size is 111 , according to the margin error of $5 \%$ and a confidence interval of $95 \%$. The targeted sample size required after a $10 \%$ attrition rate added was 122 . All registered OR nurses participated voluntarily in the study.

\section{Data collection}

Briefing was given to all potential participants prior to data collection. The questionnaires were distributed to the OR nurses who met the inclusion criteria. Written consent was obtained for those who willing to participate in the study. Nurses were instructed to seal in the completed questionnaire using an envelope that was provided. A box was placed in the staff lounge and labelled as 'Job Satisfaction Survey' for nurses to return the questionnaire. Data collection was conducted from $1^{\text {st }}$ August 2019 to $31^{\text {st }}$ August 2019. Approximately 122 participants $(100 \%)$ responded to the study.

The study proposal was submitted to the International Medical University Ethical Committee for approval and funding [Approved project ID: BN 1/2019(PR-11)]. Permission to collect the data was granted from the Hospital Management of the tertiary hospital in Saudi. Written consent was obtained from participants in the study. They were assured of anonymity and confidentiality of personal information. Participants were informed of their rights to withdraw 
from the study at any time through a written email.

SPSS version 25.0 was used in this study. Analysis of missing data was conducted to ensure no missing data will be included for data analysis. The descriptive statistics including mean, frequency, percentage and standard deviation were used to analyse the factors that affecting job satisfaction on OR nurses.

\section{RESULTS}

\section{Descriptive data}

In this study, 122 self-reported nurses were aged between 25 to 59 years old. The data findings showed that the mean age of the sample was $37 \pm$ SD 8.3. Majority of the nurses $(95.1 \%)$ were female. The data showed that $59.8 \%$ of nurses are married and $37.7 \%$ are single. In regard to nationality, $59 \%$ of the sample are Filipino, 36.9 are Malaysian and only 4.1\% nurses are from local Saudi and other countries. Most of the sample $(73 \%)$ had a Bachelor's Degree and higher qualification. The average clinical experience of samples was $13.5 \pm \mathrm{SD} 6.9$ years. The mean years in the current organisation was $5.9 \pm$ SD 0.36 . In terms of job position, most of the samples were Staff Nurse (SN) 2 (54.1\%). The participants' salaries ranged according to their job position, nationality and seniority. From the findings, 63.9 per cent of nurses received basic monthly salary below SAR 10,000 (RM11,400) while $36.1 \%$ reported having a salary of more than SAR of 10,000. Other demographic characteristics of the study group are shown in Table 1 .

Table 1: Demographic characteristic of the study group $(n=122)$

\begin{tabular}{|c|c|c|c|c|}
\hline \multicolumn{2}{|c|}{ DEMOGRAPHIC CHARACTERISTIC } & $\mathbf{N}$ & $\%$ & $\mathbf{M} \pm \mathbf{S D}$ \\
\hline \multicolumn{2}{|l|}{ Age in year } & & & $37 \pm 8.3$ \\
\hline \multirow[t]{2}{*}{ Gender } & Male & 6 & 4.9 & \\
\hline & Female & 116 & 95.1 & \\
\hline \multirow{3}{*}{$\begin{array}{l}\text { Marital } \\
\text { status }\end{array}$} & Married & 73 & 59.8 & \\
\hline & Divorced/Widowed & 3 & 2.5 & \\
\hline & Single & 46 & 37.7 & \\
\hline \multirow[t]{4}{*}{ Nationality } & Saudi & 1 & 0.8 & \\
\hline & Filipino & 72 & 59.0 & \\
\hline & Malaysian & 45 & 36.9 & \\
\hline & Others & 4 & 3.3 & \\
\hline
\end{tabular}

\begin{tabular}{|c|c|c|c|c|}
\hline \multirow{4}{*}{\begin{tabular}{|l|} 
Highest \\
academic \\
qualification
\end{tabular}} & Diploma in Nursing & 21 & 17.2 & \\
\hline & Post Basic Program & 12 & 9.8 & \\
\hline & $\begin{array}{l}\text { Bachelor of Science in } \\
\text { Nursing }\end{array}$ & 85 & 69.7 & \\
\hline & $\begin{array}{l}\text { Master of Science in } \\
\text { Nursing and higher }\end{array}$ & 4 & 3.3 & \\
\hline \multirow{3}{*}{$\begin{array}{l}\text { Clinical } \\
\text { experience } \\
\text { in year }\end{array}$} & $<5$ years & 3 & 2.5 & $13.5 \pm 6.9$ \\
\hline & 5 to 10 years & 52 & 42.6 & \\
\hline & $>10$ years & 67 & 54.9 & \\
\hline \multirow{3}{*}{$\begin{array}{l}\text { Years of } \\
\text { working } \\
\text { experience } \\
\text { in current } \\
\text { organisation }\end{array}$} & $<5$ years & 50 & 41.0 & $5.9 \pm 0.36$ \\
\hline & 5 to 10 years & 57 & 46.7 & \\
\hline & $>10$ years & 12 & 12.3 & \\
\hline \multirow[t]{2}{*}{ Position } & SN 1 & 56 & 45.9 & \\
\hline & SN 2 & 66 & 54.1 & \\
\hline \multirow[t]{4}{*}{ Basic salary } & Below SAR 10,000 & 78 & 63.9 & \\
\hline & SAR 10,001-SAR 12,000 & 19 & 15.6 & \\
\hline & SAR 12,001-SAR 15,000 & 20 & 16.4 & \\
\hline & Above SAR 15,000 & 5 & 4.1 & \\
\hline \multirow[t]{5}{*}{$\begin{array}{l}\text { Work-life } \\
\text { balance }\end{array}$} & $\begin{array}{l}\text { Very } \\
\text { dissatisfied }\end{array}$ & 1 & 0.8 & \\
\hline & Dissatisfied & 9 & 7.4 & \\
\hline & Neutral & 53 & 43.4 & \\
\hline & Satisfied & 54 & 44.3 & \\
\hline & $\begin{array}{l}\text { Very } \\
\text { satisfied }\end{array}$ & 5 & 4.1 & \\
\hline
\end{tabular}

\section{Intrinsic (motivation) factors}

Intrinsic (motivation) factors included activity, independence, variety, moral value, social service, authority, ability utilisation, advancement, responsibilities, creativity, recognition and achievement. Data analysis showed that the overall mean satisfaction score for intrinsic factors was $3.283 \pm \mathrm{SD} 0.67$; with the highest mean score reported for utilisation of ability $(\mathrm{M}=3.525$, $\mathrm{SD}=0.95$ ); and the lowest mean score was for recognition $(\mathrm{M}=2.762, \mathrm{SD}=0.95)$. Table 2 described the overall mean satisfaction score for intrinsic (motivation) factors.

Table 2: Overall Mean Satisfaction Score for Intrinsic (Motivation) Factors $(n=122)$

\begin{tabular}{|l|c|c|}
\hline Intrinsic (Motivation) Factors & Mean & Std. Deviation \\
\hline Activity & 3.352 & 0.8021 \\
\hline Independence & 3.303 & 0.8321 \\
\hline Variety & 3.385 & 0.8376 \\
\hline Moral value & 3.434 & 0.9270 \\
\hline Social service & 3.516 & 0.9021 \\
\hline Authority & 3.246 & 0.8163 \\
\hline
\end{tabular}




\begin{tabular}{|l|c|c|}
\hline Utilisation of ability & 3.525 & 0.9466 \\
\hline Advancement & 2.934 & 0.9937 \\
\hline Responsibility & 3.311 & 0.9189 \\
\hline Creativity & 3.230 & 0.8410 \\
\hline Recognition & 2.762 & 0.9452 \\
\hline Achievement & 3.402 & 0.8782 \\
\hline Overall mean score & 3.2835 & 0.67451 \\
\hline
\end{tabular}

Activity. The mean score for activity was $3.352 \pm 0.802$. The majority $(45.9 \%)$ of the nurses were neutral regarding activity in the operating room. The study showed that $41.8 \%$ of the nurses expressed satisfaction being able to keep themselves occupied all the time in their works.

Independence. Mean score for independent was $\mathrm{M}=3.303, \mathrm{SD}=0.832$. Most of the nurses $(41.8 \%)$ were neutral regarding the chance to work independently on the job. Though, $39.3 \%$ of the nurses were satisfied with the chance of being independent in work. Variety. It was found that the mean score for the variety was $\mathrm{M}=3.385$, $\mathrm{SD}=0.837$. About $42.6 \%$ of the nurses were neither satisfied nor dissatisfied regarding variety whereas, $39.3 \%$ of them indicated they were satisfied with the opportunities to do something different from time to time.

Moral value. Doing work with a good conscience reflected moral value. The mean score for moral value was $3.434 \pm 0.927$. Most of the nurses (43.4\%) were satisfied that they were able to keep a clear conscience on the job.

Social service. The opportunity of helping others reflected as social service. The mean score for social service was $3.516 \pm 0.902$. In this study, $40.2 \%$ of nurses were satisfied with the opportunity to do good for others on the job.

Authority. The chance to give orders reflected authority. From the results, less than half of nurses $(47.5 \%)$ were neutral regarding the chance to instruct people what to do. In addition, $36.9 \%$ of nurses were satisfied to give instruction in the workplace by telling others what to do.

Utilisation of Ability. The highest mean score reported in Intrinsic (Motivation) factors was utilisation of ability. The chance to utilise abilities to enhance job role reflected ability utilisation. Most of the nurses $(50.8 \%)$ were satisfied with their abilities.

Advancement. The career advancement opportunity reflected advancement. The mean score for advancement was second lowest in the Intrinsic (motivation) factor $(\mathrm{M}=2.934, \mathrm{SD}=0.993)$. The study showed that $32.8 \%$ of the nurses indicated that they were dissatisfied with the opportunities for development or improvement in this job. About $31.1 \%$ of nurses were neither satisfied nor dissatisfied regarding advancement. Moreover, almost equal percentage $(26.2 \%)$ of nurses was satisfied with the career advancement opportunity.

Responsibility. The mean score for responsibility was $3.311 \pm 0.918$. The freedom to use own judgment reflected responsibility. Most of the nurses (41.0\%) were neutral regarding responsibility. It was observed that $34.4 \%$ of the nurses were satisfied with the freedom to decide in the workplace that can be reflect their responsibility. Creativity. The mean score for creativity was $3.230 \pm 0.841$, which indicated the chance to use creative ideas at work, reflecting creativity. Most of the nurses $(46.7 \%)$ were neutral in trying their own methods of doing the job. However, $36.9 \%$ of nurses expressed satisfaction being creative in providing patient care.

Recognition. The compliment recived for doing an excellent job reflected recognition. The lowest mean score in Intrinsic (motivation) factor was recognition. The mean score for recognition was $2.762 \pm 0.945$. It was evident that $41.0 \%$ of the nurses were dissatisfied regarding the recognition they receive for a job well done. Only $27 \%$ of the nurses were satisfied that their contribution to patient care was acknowledged.

Achievement. The sense of accomplishment they got from the job reflected achievement. The mean score was $3.402 \pm 0.878$. About $42.6 \%$ of the nurses were satisfied that they are gaining a sense of accomplishment as an operating room nurse.

\section{Extrinsic (hygiene) factors}

The extrinsic (hygiene) factors consisted of 8 items (Table 3). The items related to social status, supervision (human relation), supervision (technical), security, policies and procedures, compensation, the physical environment and co-worker relationship. The data reported that the overall mean satisfaction score for extrinsic (hygiene) factors was $3.193 \pm 0.667$; with the highest mean score reported for security $(\mathrm{M}=3.541$, $\mathrm{SD}=0.844$ ), and the lowest mean score was for social status $(\mathrm{M}=2.770, \mathrm{SD}=0.942)$.

Social status. The opportunity to be promoted reflected social status. The lowest mean scores reported extrinsic (hygiene) factors was social status. The mean score was $2.770 \pm 0.942$. In this study, $48.4 \%$ of the 
nurses were neutral regarding promotion. However, $19.7 \%$ of the nurses expressed dissatisfaction, and $12.3 \%$ of them were very dissatisfied with the chance to be promoted in the department. The results indicated that 22 nurses $(18.0 \%)$ were satisfied, and only 2 nurses $(1.6 \%)$ were delighted regarding the opportunities to be promoted.

Supervision (human relation). The way the supervisor handles the nurses reflected supervision (human relation). The mean score was $3.107 \pm 0.821$. More than half of the nurses $(54.1 \%)$ remain neutral regarding supervision (human relation). However, one-quarter of the nurses were satisfied with the way the nurse supervisor handles the staff nurses.

Table 3: The overall mean score for extrinsic (Hygiene) factors $(n=122)$

\begin{tabular}{|l|c|c|}
\hline Extrinsic (hygiene) factors & Mean & $\begin{array}{c}\text { Std. } \\
\text { Deviation }\end{array}$ \\
\hline Social status & 2.770 & 0.942 \\
\hline Supervision (Human Relation) & 3.107 & 0.821 \\
\hline Supervision (Technical) & 3.221 & 0.808 \\
\hline Security & 3.541 & 0.844 \\
\hline Policies and procedures & 3.377 & 0.875 \\
\hline Compensation & 3.066 & 1.034 \\
\hline Physical environment & 3.139 & 0.855 \\
\hline Co-workers relationship & 3.328 & 0.807 \\
\hline Overall mean score & 3.193 & 0.667 \\
\hline
\end{tabular}

Supervision (technical). The decision-making skill of the supervisor at work reflected supervision (technical). The mean score was $3.221 \pm 0.808 .58$ of the nurses $(47.5 \%)$ neither satisfy nor dissatisfy regarding the ability of their supervisor in making decisions. More than one-quarter of the nurses (36.9\%) expressed satisfaction on supervision (technical). For Security, the data reported that the highest mean score in extrinsic (hygiene) factors was security; with the mean score was $3.541 \pm 0.844$. About $45.1 \%$ of the nurses were satisfied with the job offer employment stability.

Policies and procedures. The mean score was $3.377 \pm 0.875$. Majority of the nurses $(43.4 \%)$ were satisfied with hospital policies and procedures based on the implementation.

Compensation. The wage and the amount of work performed reflect compensation in extrinsic (hygiene) factor. The mean score was $3.066 \pm 1.034$. About $35.2 \%$ of the nurses reported that they were neutral regarding compensation. 29.5 per cent of the nurses feels satisfied with the salary also the amount of the work. However, $21.3 \%$ of the nurses were dissatisfied with the basic monthly salary and the amount of the work.

Physical environment. The mean score for the physical environment was $3.139 \pm 0.855$. Half of the nurses $(50 \%)$ said they were neutral regarding the working condition. Further, $31.1 \%$ of the nurses were satisfied with their work environment. Co-workers relationship. The relationship with colleagues in the OR reflected co-worker relationship. The mean score was $3.328 \pm 0.807$. Less than half of the nurses $(44.3 \%)$ were satisfied with the relationship existed among coworkers.

\section{DISCUSSION}

This study explored the factors affecting job satisfaction among operation room nurses working in a tertiary hospital, the central region of Saudi Arabia. A quantitative descriptive survey was employed to identify the job satisfaction factors among operation room nurses working in a tertiary hospital in Saudi Arabia.

A convenient sampling of 122 registered nurses in the operating were recruited in this study. The research revealed that job satisfaction of OR nurses was at a neutral level. In this study, the factors determining job satisfaction is mainly by work-life balance. The results was aligned with the information presented in the literature that workload in the operating rooms, lack of job security, and lack of motivation affected job satisfaction among nurses working in operating rooms (Admasu et al., 2018; Gillet et al., 2018; Gorgich et al., 2016; Herzberg, 2005). Other studies conducted from Saudi Arabian context indicated that variables like leadership styles, quality of life, healthcare commitment, hospital performance, and work environment influence job satisfaction levels (Al-Dossary et al., 2012; Alkassabi et al., 2018). The studies showed that nationality, years of Saudi Arabian nursing experiences, psychological states, motivating systems, and growth needs are the potential factors influencing job satisfaction among nurses. Also, peer relationship, challenging career opportunities, fringe benefits, hospital policies, poor work conditions, and lack of work recognition based on work achievement affect levels of nursing job satisfaction (Al-Dossary et al., 2012; Halcomb, Smyth \& McInnes, 2018; Tasneem et al., 2018; Zaghloul et al., 2008). 
In section $\mathrm{A}$, the participants were asked regarding participant satisfaction with the current work-life balance. Less than half of the OR nurses working in a tertiary hospital, the central region of Saudi Arabia was satisfied, and minority of them were very satisfied with the current work-life balance. Such results indicated that work-life balance has significant influence on the nurse's job satisfaction. In this study, work-life balance and job satisfaction are significantly correlated. The results are consistent with the past literature that work-life balance is related to professional life and personal life; and a lack of work-life balance could lead to job stress and job dissatisfaction (Almutairi, 2015; Higgins \& Duxbury, 2002; Buitendach \& Rothmann, 2009). Among studies that have investigated factors influencing job satisfaction, it is evident that majority of nurses (over $75 \%$ ) in operating rooms and emergency units have negative attitudes due to stressful situations. Also, the nurse reported lack of teamwork in the hospital (Alzahrani et al., 2018). However other studies that have investigated factors influencing job satisfaction among nurses in Saudi Arabia's hospitals presented contradicting results, which showed that stress has no significant relationship with job satisfaction and job performance (Al-Ahmadi, 2009). The contradicting statements thus form the basis for further research. Also, the results are congruent with past studies in which work-life balance encourages nurses to manage their personal time while maintaining balance between family, health, vacations and career (Aamir et al., 2016).

\section{Implications for Nursing Practice}

In this study, $99.2 \%$ of the participants were nonSaudis. Majority of the participant (95.1\%) were female. The study indicates that organisation support should be prioritised to promote work-life balance for the OR nurses working in a tertiary hospital in Saudi Arabia. The study provides empirical evidence on the need to enhance work-balance among nurses in tertiary hospitals to improve job satisfaction. Recounting factors influencing levels of job satisfaction allow nurse managers and policymakers in the healthcare system to design and implement medical initiatives that would further improve job satisfaction and workforce retention among nurses.

The study implied that nursing in Saudi Arabia should be promoted as an important career so that recruitment of expatriate nurses can be reduced in future. Reducing the recruitment of expatriate nurses by increasing the number of Saudi nurses could be achieved with long term strategies to strengthen education and training system for nursing profession.

\section{Limitations}

The data were collected only from one operating room nurses from Saudi Arabia, and the sample size is rather small. The findings of the study are not able to represent the population of nurses working in Saudi. Next, a quantitative study with self-administered survey was employed in this study. The self-reported data from participants may generate possible bias that could influence the findings. Future research using mix method and bigger sample size are recommended to explore other factors that may have contributed to job satisfaction among nurses.

\section{CONCLUSION}

In the study, it is evident that work-life balance influences job satisfaction among OR nurses working at a tertiary hospital in Saudi Arabia. The findings of the study provide valuable information for stakeholders in healthcare system to further enhance nurses ' work-life balance in Saudi Arabia. In this manner quality of nursing care could be improved when nurses are satisfied with their job.

\section{Conflict of Interests}

The authors declare that they have no conflict of interest.

\section{ACKNOWLEDGEMENT}

The authors are thankful to the institutional authority for completion of the work.

\section{REFERENCES}

Aamir, A., Hamid, A.B.A., Haider, M. \& Akhtar, C.S. (2016). Work-life balance, job satisfaction and nurses' retention: Moderating role of work volition. International Journal of Business Excellence, 10(4), pp 488-501.

Admasu, B.G., Temamen, T.Y., Dagmawit, B.K. \& Abdela, A.D. (2018). Job satisfaction and associated factors among nurses working in the operation theatre at government hospitals of Eastern Ethiopia, 2017. Palliative Medical Care, 5(2), pp 1-7.

Al-Ahmadi, H. (2009). Factors affecting performance of hospital nurses in Riyadh Region, Saudi Arabia. International Journal of Health Care Quality Assurance, 22(1), pp 40-54. 
Alboliteeh, M., Magarey, J. \& Wiechula, R. (2017). The profile of Saudi nursing workforce: A cross-sectional study. Nursing Research and Practice, pp 1-9.

Al-Dossary, R., Vail, J. \& Macfarlane, F. (2012). Job satisfaction of nurses in a Saudi Arabian university teaching hospital: A cross-sectional study. International Nursing Review, 59(3), pp 424-430.

Al-Mahmoud, S., Mullen, P. \& Spurgeon, P. (2012). Saudisation of the nursing workforce: Reality and myths about planning nurse training in Saudi Arabia. Journal of American Science, 8(4), pp 369-379.

Almutairi, K.M. (2015). Culture and language differences as a barrier to provision of quality care by the health workforce in Saudi Arabia. Saudi Medical Journal, 36(4), pp 425-431.

Alostaz, Z.M. (2016). Job satisfaction among critical care nurses in Al Baha, Saudi Arabia: A cross-sectional study. Gulf Medical Journal, 5(1), pp 64-68.

Alzahrani, N., Jones, R. \& Abdel-Latif, M.E. (2018). Attitudes of doctors and nurses toward patient safety within emergency departments of two Saudi Arabian hospitals. BMC Health Services Research, 18(1), 736.

Buitendach, J. \& Rothmann, S. (2009). The validation of the Minnesota Job satisfaction questionnaire in selected organisations in South Africa. SA Journal of Human Resource Management, 7(1), pp 1-8.

Gillet, N., Fouquereau, E., Coillot, H., Cougot, B., Moret, L., Dupont, S., Bonnetain, F. \& Colombat, P. (2018). The effects of work factors on nurses' job satisfaction, quality of care and turnover intentions in oncology. Journal of Advanced Nursing, 74(5), pp 1208-1219.

Gorgich, E.A.C., Arbabisarjou, A., Taji, F. \& Barfroshan, S. (2016). Job satisfaction and external effective factors in operating room nurses working educational hospitals in 2015: A cross-sectional questionnaire study. Global Journal of Health Science, 9(1), 74-81.

Grove, S.K., Gray, J.R. \& Burns, N. (2015). Understanding nursing research: Building an evidence-based practice. $6^{\text {th }}$ edition. St. Louis: Elsevier.

Halcomb, E., Smyth, E. \& McInnes, S. (2018). Job satisfaction and career intentions of registered nurses in primary health care: an integrative review. BMC Family Practice, 19(1), 136.

Herzberg, F. (2005). Motivation-hygiene theory. In J.B. Miner (Ed.), Organisational behaviour one: Essential theories of motivation and leadership (pp. 61-74). New York: ME Sharpe Inc.

Higgins, C. \& Duxbury, L. (2002). The 2001 National Work-Life Conflict Study: Report One. Retrieved from: http://www.hc-sc.gc.ca/ pphb-dgspsp/publicat/work-travail/index.html

Lamadah, S.M. \& Sayed, H.Y. (2014). Challenges facing nursing profession in Saudi Arabia. Journal of Biology, Agriculture and Healthcare, 4(7), pp 20-25.

Tasneem, S., Cagatan, A.S., Avci, M.Z. \& Basustaoglu, A.C. (2018). Job satisfaction of health service providers working in a public tertiary care hospital of Pakistan. The Open Public Health Journal, 11(1), pp 17-27

Zaghloul, A.A., Al-Hussaini, M.F. \& Al-Bassam, N.K. (2008). Intention to stay and nurses' satisfaction dimensions. Journal of Multidisciplinary Healthcare, 1, pp 51-58. 